\title{
Los seises de la Catedral de Guadix de los siglos XVI-XVII: Desarrollo, actuaciones y personajes
}

\author{
The Cathedral of Guadix's Seises in 16th-17th Centuries: \\ Development, Performances and Characters
}

\author{
Alfonso Peña Blanco \\ Universidad de Huelva. Huelva. España \\ alfonsopebla@gmail.com \\ ID ORCID 0000-0003-3122-6988
}

Resumen: En los primeros testimonios documentales de las catedrales españolas se constata la participación de grupos de niños en la organización interna y en el culto. De la misma manera, sus actuaciones iban más allá del servicio en las misas, participando igualmente en la liturgia y paraliturgia del coro, donde la música tenía una importancia capital. No obstante, a partir del siglo $\mathrm{xV}$, los cambios introducidos en la música que se interpretaba en estos centros religiosos obligaron a la progresiva profesionalización de estos niños cantores, dando lugar a un grupo de mozos de coro o seises, cuya misión principal fue la de interpretar la primera y segunda voz de la música polifónica. En este trabajo damos a conocer el desarrollo y los protagonistas de este grupo de cantores en la sede accitana en los siglos XVI-XVII, analizando la catedral como un espacio de aprendizaje y promoción; ya que muchos de ellos provenían de estratos sociales marginados.

Palabras clave: catedral de Guadix; siglos XVI-XVII, seises, capilla de música, maestro de capilla; polifonía.
Abstract: In the first documentary testimonies of the Spanish cathedrals, the participation of groups of children in the internal organization and in the cult is verified. In the same way, his performances went beyond the service at masses, also participating in the liturgy of the choir and altar, where music was of capital importance. However, from the 15th century, the changes introduced in the music that was performed in these religious centers forced the progressive professionalization of these singing children, giving rise to a group of choir boys or "seises", whose main mission was to interpret the first and second voices of polyphonic music. In this work, we present the development and protagonists of this group of singers in the Accitan headquarters in the 16th17th centuries, analyzing the cathedral as a space for training and promotion for many of them, since it came from marginalized social strata.

Keywords: Guadix's cathedral; 16th-17th centuries; seises; music chapel; chapel master; polyphony. 


\section{INTRODUCCIÓN}

En la actualidad, en lugares como la ciudad de Sevilla, cuando se habla de seises se hace en alusión al grupo de niños que danzan en la catedral en las festividades del triduo de Carnaval, Corpus Christi y la Inmaculada Concepción. Sin embargo, históricamente es impreciso identificar a los seises solo con niños danzantes; ya que, esencialmente, el término seise hace referencia a los niños cantores de las capillas de música de las catedrales, existiendo en casi la totalidad de sedes españolas. ${ }^{1}$ De esta forma, pese a que el número de estos cantores osciló entre cuatro y diez niños, se generalizó el número de seis. ${ }^{2}$ Por este motivo, el término seises no es sino el plural vulgarizado de seis niños cantores, siendo una denominación que durante el siglo XVI se generalizó en toda España. ${ }^{3}$

No obstante, la terminología empleada en las fuentes para designar a estos niños cantores es algo ambigua, apareciendo términos como cantorcicos o mozos de coro, para referirse tanto a los seises como a los niños que servían en el coro de los oficios o en el altar. No fue hasta el siglo XVI, cuando empezó a emplearse el título de seises referido a los niños que participaban en algunas partes del oficio divino y la música polifónica; aunque se siguieron empleando los términos anteriores. De hecho, hasta finales del siglo XVI, en las fuentes de la

1 Sobre la terminología y existencia de niños cantores en las catedrales españolas, véase, por ejemplo, José López-CALO, La música en las catedrales españolas, Madrid, Instituto Complutense de Ciencias Musicales, 2012, 220. Javier RuzZ JimÉnez, "From mozos de coro towards seises boys in the musical life of Sevilla cathedral in the fifteenth and sixteenth centuries", en Susan BOYTON - Eric RicE (eds.), Young Choristers, 650-1700, Nueva York, The Boydell Press, 2008, 86-103. Samuel Rubio Calzón, Historia de la música española: desde el Ars Nova hasta 1600, vol. II, Madrid, Alianza, 2004, 28-37. Herminio González Barrionuevo, Los seises de la catedral de Sevilla, Sevilla, Castillejo, 1992, 29-34.

2 Cf. Rubio Calzón, Historia de la música española, 30-39. Herminio González BARRIONUEVo, Francisco Guerrero (1528-1599), vida y obra. La música en la catedral de Sevilla a finales del siglo XVI, Sevilla, Cabildo Metropolitano de la Catedral de Sevilla, 2000, 134-138.IDEM, Los seises, 33-38. Sonsoles RAmos AHIJADo, La catedral de Ávila como institución musical durante la segunda mitad del siglo XVII. Salamanca, Universidad de Salamanca, 2011,194-195. Marcelino Díez MarTínez, “La música en la Catedral de Cádiz y su proyección urbana durante el siglo XVIII: tradición e innovación en una ciudad cosmopolita", Revista de Musicología 26 (2003) 313-320.

3 Cf. González Barrionuevo, Los seises, 34. 
catedral de Sevilla aparece indistintamente mozos de coro y seises para referirse a estos niños cantores. En cambio, en la catedral de Granada, centro religioso más importante próximo a Guadix, su Consueta distingue perfectamente las obligaciones y competencias de mozos de coro y seises como dos tipos de servidores distintos. ${ }^{4}$

Con referencia a la sede accitana, la conformación de un grupo de seises como tal fue bastante tardía, en torno a $1620 . .^{5}$ Pese a esto, las referencias más antiguas que se conservan en esta catedral nos permiten concluir la existencia de niños cantores, al menos, desde el primer maestro de capilla del que tenemos noticias, Francisco Maldonado (1545-1570). ${ }^{6}$ Junto a este dato, la Consueta de Guadix, fechada en 1557, es una fuente esencial para establecer tanto el posible origen como las funciones de su grupo de seises. ${ }^{7}$ A este respecto, cabe señalar que una consueta es un documento de tipo litúrgico-administrativo en el que se recogen todas las competencias y obligaciones de las dignidades y servidores en el culto y administración de una determinada catedral. En este caso, la Consueta de la sede accitana aborda todo lo referente a las funciones de sus mozos de coro, acólitos y versicularios, tanto en la interpretación del canto llano del oficio divino, como en el servicio en el altar y coro de los oficios. ${ }^{8}$ Dentro de este bloque, tan solo en una ocasión, en el capítulo dedicado al hábito de los integrantes del coro de los oficios, aparece

4 Archivo de la Catedral de Granada (en adelante ACG). Consueta de ceremonias y gobierno, de la Santa Iglesia Catedral, Apostólica y Metropolitana, de la ciudad de Granada. Granada, Imprenta de D. Nicolás Moreno, 1819, 48. Cf. GonZÁLEZ BARRIONuEVo, Los seises, 31-32.

5 Cf. Alfonso Peña Blanco. La música en la Catedral de Guadix en los siglos XV-XVII, Huelva, Universidad de Huelva, 2018, 254-255.

6 Cf. Archivo Histórico Diocesano de Guadix (en adelante AHDGu). Actas capitulares, Tomo 1, f. 7r (Cabildo de 22-10-1545).

7 AHDGu. Documentos Especiales de la catedral, carpeta n. ${ }^{\circ}$ 1, n. ${ }^{\circ}$ doc. 1 : Consueta o recollectade las ceremonias y buen orden tocante al culto diuino y otras cosas pertenecientes al buen gobierno de la sancta iglesia cathedral de Guadix hecha por el muy ilustre y reverendisimo señor don Martin de Ayala obispo de la sancta iglesia. Con acuerdo y consentimiento de los muy reverendos señores dean y cabildo de ella, 1557. Junto a este original manuscrito, el archivo diocesano conserva dos traslados manuscritos encuadernados, uno fechado en 1660 y otro coetáneo sin fecha. Además, se conserva otro traslado manuscrito incompleto y datable a principios del siglo XVII.

8 AHDGu. Consueta..., cap. 20, fol. 19r, cap. 34, fols. 35r-35v, cap. 38, fol. 40r, cap. 39 , fols. $40 \mathrm{v}-41 \mathrm{v}$, cap. 40 , fol. 42 r, cap. 52 , fol. $43 \mathrm{v}$, cap. 81 , fol. $91 \mathrm{r}$. 
el término seise, al señalar que "los mozos de choro que sirven de seises podran traer la hopas i bonetes colorados". ${ }^{\text {? }}$

Desde el punto de vista musical, las catedrales españolas funcionaron de manera análoga. ${ }^{10}$ Así, junto al coro de los oficios, que era el encargado de la interpretación del canto llano, contaban con una capilla de música, dedicada a la interpretación de la música polifónica (canto de órgano). Por tanto, a partir del dato anterior de la Consueta de Guadix, deducimos que, al menos en 1557, su catedral contaba con una capilla de música consolidada en la que intervendrían estos niños cantores. En ella, y como era habitual en nuestro país, tendrían la función de interpretar algunas partes del oficio divino, como responsorios y versículos, y la voz de soprano o tiple y la de contralto o alto de la música polifónica. ${ }^{11}$ No obstante, el uso del término seises no se generalizó en las fuentes de la catedral de Guadix hasta el establecimiento de un grupo consolidado de niños cantores, en torno al segundo cuarto del siglo XVII. ${ }^{12}$

\section{MECANISMOS DE SELECCIÓN E INGRESO}

$\mathrm{Al}$ igual que en la catedral de Sevilla y otras sedes españolas, en los procesos de selección de estos niños, el maestro de capilla era el encargado de buscar y examinar a los futuros seises de la capilla musical accitana. ${ }^{13}$ Pese a no tener datos concretos hasta el segundo cuarto del siglo XVII, por lo dispuesto en la Consueta de Guadix y otras fuentes, deducimos que los maestros de capilla anteriores a esa fecha habían tenido esta responsabilidad. ${ }^{14}$ Sin embargo, los mecanismos empleados variaban considerablemente de una sede a otra, dependiendo de sus posibilidades económicas. Así, mientras que en el siglo XVII en la catedral hispalense encontramos una nómina de seises provenientes

\footnotetext{
9 AHDGu. Consueta..., cap. 92, f. 108r.

10 Cf.Victoriano José Pérez MAnCilla, "El patrimonio musical”, en Antonio Fajardo Ruz (coord.). La Catedral de Guadix: Magna Splendore. Granada, Mouliaá Map, 2007, 400-401.

11 Cf. GonzÁlez Barrionuevo, Francisco Guerrero, 135.

12 AHDGu. Actas Capitulares, Tomo 10, f. 55r (Cabildo de 2-6-1620).

13 Cf. González Barrionuevo, Los seises, 41. López-Calo, La música, 220-222. Peña BlANCO, La música, 144-145.

14 AHDGu. Actas Capitulares, Tomo 1, f. 189r (Cabildo de 19-1-1579). Cuentas de Fábrica Mayor, caja 2979-a, Libro I (1556-1586), ff. 402r, 412v, 434r, 436r, 442r y 469r.
} 
de toda la geografía española e, incluso, Portugal, en la sede accitana eran buscados por poblaciones más o menos cercanas a Guadix. ${ }^{15}$ No obstante, también hubo seises que llegaron de lugares más alejados (Murcia, Córdoba, Granada, Alhama, Baeza, Jódar y Paterna) y otros que eran familiares de miembros de la capilla de música: cantores adultos y ministriles (instrumentistas). ${ }^{16} \mathrm{~A}$ este respecto, cabe indicar que un buen número de estos niños cantores procedían de poblaciones con instituciones religiosas más o menos importantes y con cierta actividad musical. De hecho, un alto porcentaje de los seises de la catedral de Guadix del siglo XVII eran naturales de Úbeda y habían sido formados en la capilla del Salvador, que contaba con capilla de música propia. ${ }^{17}$

Así, los maestros de capilla accitanos, o alguien delegado por ellos, eran enviados por distintas zonas próximas para reclutar a los aspirantes a seises. De hecho, un acta de 1687 recoge cómo el maestro Bartolomé de Alaminos delegó en el ministril Fernando Dávalos para que bajara "a la ciudad de Úbeda y otras partes y busque muchachos de hasta ocho años para seises" ${ }^{18}$ A partir de esta referencia comprobamos además la media de edad con la que ingresaban estos niños cantores en la capilla de música accitana; por lo que permanecían una media de 6 o 7 años al servicio de la catedral, hasta que

15 AHDGu. Actas Capitulares, Tomo 10, f. 179v (Cabildo de 25-1-1622), Tomo 10, f. 446v (Cabildo de 19-11-1624), Tomo 11, f. 12r (Cabildo de 4-2-1625), Tomo 11, f. 63v (Cabildo de 4-7-1625), Tomo 11, f. 465v (Cabildo de 17-12-1628), Tomo 12, f. 88v (Cabildo de 28-9-1629), Tomo 13, f. 459v (Cabildo de 9-10-1637), Tomo 13, f. 593v (Cabildo de 13-9-1639), Tomo 14, f. 249v (Cabildo de 1-7-1644), Tomo 14, f. 321r (Cabildo de 14-2-1645), Tomo 14, f. 494r (Cabildo de 13-11-1646), Tomo 14, f. 496r (Cabildo de 23-11-1646), Tomo 18, f. 39r (Cabildo de 11-3-1665), Tomo 18, f. 310r (Cabildo de 20-3-1665), Tomo 19, f. 475r (Cabildo de 21-5-1668), Tomo 22, f. 179r (Cabildo de 5-7-1679). Cf. GonzÁlez Barrionuevo, Los seises, 41-42.

16 AHDGu. Actas Capitulares, Tomo 12, f. 88v (Cabildo de 10-10-1629), Tomo 11, f. 463r (Cabildo de 27-11-1627), Tomo 21, f. 218r (Cabildo de 2-7-1678).

17 AHDGu. Actas Capitulares, Tomo 11, f. 112v (Cabildo de 26-1-1626), Tomo 13, f. 392v (Cabildo de 9-1-1637), Tomo 14, f. 496r (Cabildo de 23-11-1646), Tomo 19, f. 475r (Cabildo de 21-5-1668), Tomo 23, f. 65r (Cabildo de 10-5-1687), Tomo 23, f. 318r (Cabildo de 28-5-1691). Javier MARín LóPEz, "Music regulations and sacred repertories in a ducal town without a duke: Francisco de los Cobos and the Sacra Capilla of El Salvador in Sixtennth-century Ubeda", en Tess KNIGHTON y Ascensión Mazuela Anguita (coords.), Hearing the city in early modern Europe, Turnhout, Brepols, 2018, 241-276.

18 Ibid., Tomo 23, f. 65r (Cabildo de 10-5-1687). 
mudaban la voz. Quizás pueda llamar la atención la temprana edad con la que estos niños abandonaron su lugar natal para pasar a estar custodiados por el maestro de capilla en la catedral de Guadix, pero para muchos de ellos, provenientes de estratos sociales muy diversos, esto supuso una oportunidad para labrarse una proyección profesional en el campo de la música. ${ }^{19}$

$\mathrm{Al}$ igual que en la catedral de Sevilla, cuando los aspirantes a seises llegaban a la sede accitana eran examinados por el maestro de capilla en el coro o en otras dependencias catedralicias..$^{20}$ De igual manera, tras este primer examen, debían pasar a la sala capitular para hacer demostración de sus cualidades ante el cabildo, quien ratificaba la decisión del maestro o, por el contrario, dictaminaba el despido de los candidatos a seises. ${ }^{21}$ Pese a esto, los datos recogidos en las fuentes conservadas en la catedral de Guadix solo se limitan a registrar el ingreso y el salario asignado a los nuevos seises, sin detallar apenas nada del proceso de selección. Sin embargo, encontramos un acta capitular de 1696 que recoge de manera más detallada el procedimiento llevado a cabo y en la que se describe lo siguiente:

En este cabildo propuso el señor dean y dixo como ya sabe el cabildo an traido dos seises de Baza, los quales abian cantando en el choro y el maestro de capilla los abia examinado y reconocido, que viera el cabildo si se avian de recibir atento a las faltas que ay de estas voces.Y oyda esta

19 Cf. Peña Blanco, La música, 258-259.

20 Sobre los procesos de selección de seises llevados a cabo por los maestros de capilla de la catedral de Guadix, véase AHDGu. Actas Capitulares, Tomo 10, f. 55r (Cabildo de 10-6-1620), Tomo 10, f. 112v (Cabildo de 26-1-1621), Tomo 10, f. 179v (Cabildo de 21-1-1622), Tomo 12, f. 67v (Cabildo de 10-7-1629), Tomo 12, f. 423v (Cabildo de 13-5-1631), Tomo 14, f. 466v (Cabildo de 14-8-1646), Tomo 15, f. 160r (Cabildo de 7-8-1648), Tomo 16, f. 405v (Cabildo de 27-10-1656), Tomo 18, f. 255r (Cabildo de 12-8-1664), Tomo18, ff. 394r-395r (Cabildo de 202-1666), Tomo 19, f. 475r (Cabildo de 21-5-1668), Tomo 19, f. 527r (Cabildo de 14-10-1670), Tomo 22, f. 184r (Cabildo de 23-7-1680), Tomo 22, f. 359r (Cabildo de 26-2-1685), Tomo 22, f. 507r (Cabildo de 23-10-1675), Tomo 23, f. 88r (Cabildo de 7-11-1687), Tomo 23, f. 318r (Cabildo de 6-6-1691), Tomo 24, ff. 302r-302v (Cabildo de 23-7-1700). Libros del Punto, caja 2958, Libro VII (1626-1633), s/f (julio, 1629, noviembre, 1630, agosto, 1632), caja 2990, Libro VIII (1633-1647), s/f (diciembre, 1637), caja 2991, Libro IX (1659-1664), s/f (diciembre, 1660, octubre, 1664), caja 2992, Libro X (1664-1670), s/f (octubre, 1670), caja 2994, Libro XII (1679-1681), s/f (junio, 1681, julio, 1681), caja 2995, Libro XIII (1682-1686), s/f (septiembre, 1683, noviembre, 1685). Cf. GonzÁlez BARRionuevo, Los seises, 42-43. 
propuesta mandaron llamar al dicho maestro de capilla y dichos dos seises, y todos entraron en el cabildo y de nuevo volvieron a cantar cada uno una copla, y el maestro informo a dichos señores y dixo que le abian parecido muy buenas voces y serian mexores con el exercicio, y tenian la conveniencia de saber canto llano los dichos seises y principios de canto de organo que decia se podian recibir los dos, y aviendose salido los dichos señores tratado y conferido acordaron recibir y con efecto recibieron a Juan de Torres y Pedro Antonio por seises de la capilla de musica de esta santa iglesia. ${ }^{22}$

Como se desprende del análisis de esta referencia, el mecanismo de selección llevado a cabo por el maestro de capilla de Guadix seguía el mismo orden que el realizado en otras sedes como León, Segorbe o Sevilla. ${ }^{23}$ Así, el examen al que se sometía a los futuros aspirantes a seises constaba de dos partes: una realizada ante el maestro de capilla y otra ante el cabildo. En ambos casos, la prueba consistió en la interpretación de una copla; aunque debemos deducir que la llevada a cabo por el maestro de capilla fue más extensa y contó con varias partes; ya que da razón de que ambos aspirantes tenían conocimientos de canto llano y polifonía. No obstante, al igual que en la catedral de Sevilla, el elemento determinante para ingresar en la capilla de música accitana fue que poseían buenas facultades vocales; por lo que, una vez estuvieran bajo la tutela del maestro de capilla, completarían su formación musical. ${ }^{24}$

\section{FUNCIONES DEL GRUPO DE SEISES Y SU PROYECCIÓN PROFESIONAL}

En relación con las funciones y servicios que desempeñaban el grupo de niños cantores, hay que señalar que eran más o menos análogas en todas las catedrales españolas. ${ }^{25}$ Así, en la mayoría de consuetas y

\footnotetext{
22 AHDGu. Actas Capitulares, Tomo 24, f. 95r (Cabildo de 15-2-1696).

23 Cf. González Barrionuevo, Los seises, 41-43. Buenaventura Delgado Criado, Historia de la educación en España y América: la educación en la Hispania Antigua y Medieval, Madrid, Morata, 2002, 544. María Dolores CAmpos SánChez-BordonA - Ignacio González-Varas IbáÑez - María Dolores Teijeira Pablos, Arte, función y símbolo: El coro de la catedral de León, León, Universidad de León, 2000, 57-58.

24 Cf. González Barrionuevo, Los seises, 42. Bernabé Bartolomé Martínez, "Enseñanza de la Música en las Catedrales", Anuario de Estudios Medievales 21 (1991) 607-628.

25 Cf. López-CAlo, La música, 220-221. GonzÁlez Barrionuevo, Los seises, 44-45.
} 
reglamentos de seises aparecen las mismas partes de la liturgia de la misa y del oficio divino que debían interpretar, como sus actuaciones en la paraliturgia con motivo de las solemnidades más importantes, principalmente Navidad y Corpus. De hecho, en la catedral de Sevilla estas funciones se mantuvieron hasta principios del siglo $\mathrm{XX}$ y en otras, como la de Granada, también aparece la obligación de danzar en distintas festividades.

Con referencia a la catedral de Guadix, en su consueta se detallan las partes del oficio divino que debían cantar los seises en canto llano, como versículos y responsorios, y en el resto de fuentes su participación como cantores de la capilla de música, interpretando la música polifónica. ${ }^{26}$ Por este último motivo, el estudio de canto de órgano (polifonía) y contrapunto suponían las materias más importantes de su formación musical, recibida de manos del maestro de capilla. ${ }^{27}$

Además, en el caso de la capilla de música accitana de esa época, el servicio de los seises como cantores fue un elemento esencial. La profunda crisis económica que atravesó la fábrica y la mesa capitular de la catedral de Guadix durante el siglo xvII, afectó de manera decisiva en su capilla de música. ${ }^{28}$ Durante este lapso de tiempo, estuvo muy mermada en medios y por la avanzada edad de sus miembros, contando tan solo con un cantor adulto tiple y otro alto de media. Por esta razón, la participación de los seises como cantores se hizo imprescindible, actuando activamente junto al resto de cantores siempre que la capilla de música era requerida.

De entre estas actuaciones, las más importantes eran los villancicos que se cantaban en las solemnidades principales del calendario litúrgico, esencialmente Navidad, Epifanía, Corpus Christi y su octava. ${ }^{29}$ Por lo general, en las catedrales españolas se seguía la costumbre, en estas solemnidades, de sustituir los nueve nocturnos

26 AHDGu. Consueta..., cap. 20, f. 19r, cap. 34, ff. 35r-35v, cap. 38, f. 40r, cap. 39, ff. 40v-41v, cap. 40, f. 42r, cap. 52, f. 43v, cap. 81, f. 91 r.

27 AHDGu. Actas Capitulares, Tomo 4, f. 134r (Cabildo de 21-1-1594), Tomo 6, f. 274r (Cabildo de 6-4-1604), Tomo 12, fol.751r (Cabildo de 17-12-1633). Libros del Punto, caja 2954, Libro IV (1579-1587), s/f (enero-junio, 1580). Cuentas de Fábrica Mayor, caja 2979-a, Libro I (1556-1586), fol. 634r.

28 Cf. Peña Blanco, La música, 182-185, 202-203, 233-248, 435-436.

29 AHDGu. Actas Capitulares, Tomo 12, f. 549r (Cabildo de 5-7-1633), Tomo 13, f. 69r (Cabildo de 20-12-1634), Tomo 13, f. 258r (Cabildo de 12-2-1636), Tomo 13, ff. 480v-481r (Cabildo de 29-8-1637), Tomo 14, f. 147v (Cabildo de 2-1-1644). 
del oficio de maitines por ochos villancicos y el Te Deum, convirtiéndose en momentos musicales muy apreciados en su tiempo. ${ }^{30}$ Junto a los villancicos, las otras actuaciones más destacadas en las que intervenían la capilla de música eran los aniversarios y dotaciones fundadas en la catedral y en las que se había dispuesto la presencia de música polifónica, como las misas de difuntos o como el rito de la salve los sábados. ${ }^{31}$

De igual manera, el grupo de seises, con el resto de componentes de la capilla de música, participaba del circuito de los llamados percances, es decir, las actuaciones en fiestas, tanto civiles como religiosas, que se daban en la ciudad de Guadix y en poblaciones más o menos cercanas. ${ }^{32}$ Por el contrario, pese a que en este tipo de festividades se dieron danzas, bailes o los llamados regocijos, hasta la fecha no hemos encontrado en las fuentes de la catedral de Guadix y otros archivos algún dato que corrobore la participación de estos niños cantores como danzantes. ${ }^{33}$

Por otra parte, para los seises, su servicio como cantores de la capilla de música estaba supeditado al cambio de voz. Debido a este motivo, en la mayoría de catedralesse intentaron establecer distintas vías para garantizar la formación y proyección profesional de estos

30 Cf. Peña Blanco, La música, 379-380. Lothar Siemens Hernández, "Villancicos representados en el siglo XVII: el de ángeles y pastores de Diego Durón (1692)", Revista de Musicología 10 (1987) 547-559.

31 AHDGu. Actas Capitulares, Tomo 10, ff. 147v-148r (Cabildo de 17-7-1621), Tomo 11, f. 9v (Cabildo de 31-1-1625), Tomo 11, f. 241r (Cabildo de 29-12-1626), Tomo 11, ff. 319r-319v (Cabildo de 8-10-1627), Tomo 12, f. 309v (Cabildo de 23-8-1630), Tomo 13, f. 550v (Cabildo de 3-2-1639), Tomo 14, f. 19r (Cabildo de 11-10-1641), Tomo 18, f. 485r (Cabildo de 24-5-1667). Cuentas de Fábrica Mayor, caja 2980, Libro VII (1650-1674), ff. 52r y 83r, caja 1097, Libro II (1675), f. 13r.

32 AHDGu. Actas Capitulares, Tomo 11, f. 9v (Cabildo de 31-1-1625), Tomo 11, f. 241r (Cabildo de 29-12-1626), Tomo 11, ff. 319r-319v (Cabildo de 8-10-1627), Tomo 12, f. 309v (Cabildo de 23-8-1630), Tomo 13, f. 550v (Cabildo de 3-2-1639), Tomo 14, f. 19r (Cabildo de 11-10-1641). Cf. López-CaLo, La música, 311-329. Paulino CAPdepón Verdú, “Matías Navarro (1668?-1727), maestro de capilla de la catedral de Orihuela", Revista de Musicología 21 (1998) 169-196.

33 En un acta capitular de 1630, por ejemplo, se recoge una descripción detallada de todos los fastos organizados por el cabildo de la catedral para la solemnidad de la Inmaculada Concepción. Pese a que se especifica la ejecución de danzas, no describe que intervinieran seises como danzantes, véase AHDGu. Actas Capitulares, Tomo 12, ff. 340v-341r (Cabildo de 31-10-1630). 
niños llegados a ese momento. ${ }^{34}$ Así, los seises que se encontraban en esta situación tenían, por lo general, tres posibles alternativas: regresar a sus hogares, ingresar como aprendices de la capilla de música, en calidad de cantores o ministriles, o emprender la carrera eclesiástica. Por ejemplo, en el caso de la catedral de Sevilla, desde la segunda mitad del siglo XVI, los antiguos seises tuvieron la oportunidad de beneficiarse de una beca de dos o tres años para ingresar en el colegio de San Isidoro, además de una ayuda de costa para el vestido. ${ }^{35}$ Por el contrario, para aquellos que decidieron regresar a sus casas, tanto el cabildo de la catedral de Sevilla como el de Guadix actuaron de la misma manera: otorgando una ayuda de costa para que se compraran un vestuario nuevo y poder regresar a sus lugares de origen. ${ }^{36}$

Para aquellos que decidieron permanecer en la catedral, hubo casos, como también ocurrió en la sede hispalense, de alguno de estos niños cantores que permanecieron al servicio de la capilla de música en calidad de $e x$-seises, percibiendo por ello un exiguo salario y sin llegar a ingresar como cantores adultos. ${ }^{37}$ Sin embargo, la mayoría pasó a servir como aprendices de ministriles, organistas o cantores de la capilla de música. ${ }^{38}$ En cambio, para aquellos que se decantaron por iniciar la carrera eclesiástica, el cabildo accitano otorgó una serie de becas a los que demostraron tener cualidades para la interpretación del canto llano. ${ }^{39}$ Con esta medida, se garantizaba disponer en un futuro de músicos profesionales que sirvieran en el coro de los

34 Cf. López-CAlo, La música, 221. Javier Ruiz JiméNez, La librería de canto de órgano: creación y pervivencia del repertorio del renacimiento en la actividad musical de la catedral de Sevilla, Sevilla, Junta de Andalucía. Consejería de Cultura, 2007, 205207. González Barrionuevo, Los seises, 51-52.

35 Cf. González Barrionuevo, Los seises, 52-53.

36 AHDGu. Actas Capitulares, Tomo 19, f. 527r (Cabildo de 14-10-1670), Tomo 19, f. 558v (Cabildo de 2-3-1671), Tomo 22, f. 184r (Cabildo de 23-7-1680). Cf. GonZÁlez BARrionueVo, Los seises, 51.

37 AHDGu. Actas Capitulares, Tomo 10, f. 134r (Cabildo de 7-5-1621), Tomo 13, ff. 390r-391v (Cabildo de 2-1-1637). Cf. González Barrionuevo, Los seises, 51.

38 AHDGu. Actas Capitulares, Tomo 14, f. 249v (Cabildo de 1-7-1644), Tomo 21, f. 279v (Cabildo de 23-12-1678). Libros del Punto, caja 2995, Libro XIII (16821686), s/f (octubre, 1682).

39 AHDGu. Actas Capitulares, Tomo 12, f. 438r (Cabildo de 1-8-1628), Tomo 12, f. 317r (Cabildo de 10-9-1630), Tomo 12, f. 711v (Cabildo de 31-10-1633), Tomo 14, f. 75r (Cabildo de 14-2-1634), Tomo 21, f. 431r (Cabildo de 6-12-1677), Tomo 22, f. 359r (Cabildo de 25-1-1684). Libros del Punto, caja 2973, Libro XI (1670-1676), s/f (noviembre, 1672). 
oficios de la catedral y en su capilla de música. De hecho, algunos de estos antiguos seises llegaron a desempeñar el cargo de sochantre de la catedral accitana y en otros centros religiosos importantes, a los que llegaron después de ganar una oposición. ${ }^{40}$

\section{RETRIBUCIONES ORDINARIAS Y EXTRAORDINARIAS DE LOS SEISES}

Por ser miembros de la capilla de música, los seises de Guadix percibían una serie de ingresos por su servicio como cantores; aunque debemos distinguir entre los destinados para su manutención de los que recibían de manera extraordinaria. ${ }^{41} \mathrm{Al}$ igual que en el resto de catedrales, como las de Sevilla, Cádiz o Toledo, el gasto derivado de su manutención y enseñanza era sufragado por el cabildo catedral. En el caso de la sede accitana, el deán era el encargado de administrar todo lo necesario para el vestido de los niños cantores, como procurar su atención médica en el vecino Hospital Real, institución que también dependía del cabildo. ${ }^{42}$ De la misma manera, como también ocurría en la catedral hispalense, el maestro de capilla percibía un salario complementario destinado al cuidado y educación del grupo de seises, teniendo la obligación de custodiarlos en su mismo domicilio. ${ }^{43}$ A este respecto, cabe decir que no solo tenía la responsabilidad de

40 AHDGu. Actas Capitulares, Tomo 11, ff. 434v-435r (Cabildo de 21-7-1628), Tomo 12, f. 562r (Cabildo de 23-4-1632), Tomo 13, f. 39v (Cabildo de 4-7-1634), Tomo 14, ff. 427v-428r (Cabildo de 4-4-1646), Tomo 23, f. 167v (Cabildo de 9-1-1688).

41 Cf. Peña Blanco, La música, 260-262.

42 AHDGu. Actas Capitulares, Tomo 10, f. 116v (Cabildo de 13-2-1621), Tomo 10, f. 160r (Cabildo de 24-9-1621), Tomo 10, f. 206r (Cabildo de 24-5-1622), Tomo 11, ff. 103r-103v (Cabildo de 3-10-1625), Tomo11, f. 336v (Cabildo de 23-11-1627), Tomo 12, f. 154v (Cabildo de 4-12-1629), Tomo 12, ff. 245r-245v (Cabildo de 7-61630), Tomo 12, f. 441r (Cabildo de 8-7-1631), Tomo 12, f. 520v (Cabildo de 161-1632), Tomo 13, f. 69r (Cabildo de 20-12-1634), Tomo 15, f. 88v (Cabildo de 24-1-1648), Tomo 15, f. 450r (Cabildo de 19-3-1652), Tomo 16, f. 274v (Cabildo de 25-6-1655), Tomo 16, f. 355v (Cabildo de 5-5-1656), Tomo 22, f. 45r (Cabildo de 22-6-1679), Tomo 22, f. 215r (Cabildo de 5-11-1680). Cuentas de Fábrica Mayor, caja 900, Contabilidad de Fábrica y Obra II (1630-1633), f. 8v. Cf. PeÑa Blanco, La música, 47-48.

43 AHDGu. Actas Capitulares, Tomo 12, f. 67v (Cabildo de 10-7-1629), Tomo 12, f. 549r (Cabildo de 9-3-1632), Tomo 14, f. 249v (Cabildo de 1-7-1644). Libros del Punto, caja 2958, Libro VII (1626-1633), s/f (noviembre, 1630). Cf. GonZÁLEZ Barrionuevo, Los seises, 47-48. Ruiz Jiménez,"From mozos de coro", 28-37. 
enseñarles música, canto de órgano (polifonía) y contrapunto, sino además instruirlos en gramática y religión. ${ }^{44}$

Sin embargo, al igual que lo que ocurría en la catedral de Sevilla en esta época, los gastos provocados por la manutención del grupo de seises excedían en muchas ocasiones las partidas anuales destinadas a tal fin. ${ }^{45}$ Con objeto de evitar las llamadas ayudas de costa y regular de esta manera los gastos, el cabildo accitano decidió en 1675suministrar todo lo necesario para el vestido de los seises (ropa, medias, zapatos, sombreros, capas...) dos veces al año, coincidiendo con las dos festividades principales para el grupo de estos niños cantores: Navidad y Corpus Christi. ${ }^{46}$ De esta manera, se logró regular la partida destinada por el cabildo para el cuidado de los seises y descendieron considerablemente las peticiones de ayuda o socorro por parte de los maestros de capilla. ${ }^{47}$ Con relación a este tema, un dato curioso es que lo único que no sufragaba el cabildo era el gasto en camisas, que debían correr por cuenta de las familias de los seises. ${ }^{48}$

Como apuntábamos en otro apartado anterior, solo los datos concentrados a partir del segundo cuarto del siglo XVII nos permiten establecer, en este caso, la evolución de esas retribuciones ordinarias. Así, el salario destinado al sustento y educación del grupo de seises accitanos se incrementó de los veintitrés ducados, en 1629, a los cincuenta ducados a finales de siglo. ${ }^{49}$

No obstante, dentro de esta partida también podemos incluir un grueso debido a otras actuaciones de los seises y que podríamos denominar dotaciones especiales. Fundamentalmente, se trataba del derivado de la participación de la capilla de música en los villancicos de los maitines de Navidad y Corpus..$^{50}$ En estos casos, el grupo

44 Cf. Peña Blanco, La música, 138-145.

45 Cf. González Barrionuevo, Los seises, 48.

46 AHDGu. Actas Capitulares, Tomo 12, f. 549r (Cabildo de 5-7-1633), Tomo 12, f. 711v (Cabildo de 5-7-1633), Tomo 13, f. 69r (Cabildo de 20-12-1634), Tomo 13, f. 258r (Cabildo de 12-2-1636), Tomo 13, ff. 480v-481r (Cabildo de 29-8-1637), Tomo 14, f. 147v (Cabildo de 2-1-1644).

47 Cf. Peña Blanco, La música, 260-261.

48 AHDGu. Actas Capitulares, Tomo 21, f. 431r (Cabildo de 12-11-1675).

49 AHDGu. Actas Capitulares, Tomo 12, f. 67v (Cabildo de 10-7-1629), Tomo 12, f. 549r (Cabildo de 9-3-1632), Tomo 14, f. 249v (Cabildo de 1-7-1644). Libros del Punto, caja 2958, Libro VII (1626-1633), s/f (noviembre, 1630).

50 AHDGu. Cuentas de Fábrica Mayor, caja 900, Libro I (1613-1628), ff. 34r, 37v, 44r, 75v, 80v y 85r, caja 900, Contabilidad de Fábrica y Obra II (1630-1633), ff. 6r, 
de seises percibía una parte de la destinada a los cantores de la capilla de música, que era repartida entre cada niño. Junto a estas retribuciones, también hay que añadir las derivadas de su actuación en las dotaciones y aniversarios fundados en la catedral y en las que el reparto se hacía de igual forma, ascendiendo a la cantidad de diez ducados anuales en la segunda mitad del siglo XVII. ${ }^{51}$ Sin embargo, al contrario de la práctica llevada a cabo en la catedral de Sevilla, no consta que el cabildo catedral gratificara, a título personal, al grupo de seises por desempeñar bien sus funciones en el marco cronológico de nuestro estudio. ${ }^{52}$

Junto a estos ingresos, como en el resto de sedes españolas, también se daban otros de carácter extraordinario. De entre ellos, los más importantes eran los derivados de la participación de la capilla de música en los percances. Además, en las fuentes de la catedral accitana consta que, ocasionalmente, el grupo de seises participó de manera individual en estas salidas a distintas iglesias de Guadix, con la protesta de alguno de los miembros de la capilla de música. Este fue el caso del músico Juan Petrel, que en 1627 elevaba al cabildo una queja por"yr los seises a cantar a la Compañia [...] le sigue a la capilla de músicos gran perdida".$^{53}$ Esta referencia no hace sino constatar, como hacíamos en el apartado anterior, la falta de recursos de la capilla accitana, en la que los seises desempeñaban un papel fundamental, en comparación con otras catedrales o centros religiosos importantes, como la catedral de Sevilla o la Capilla Real de Granada, que sí tenían cantores adultos con tesituras agudas. ${ }^{54}$

Con relación a estos ingresos extraordinarios, hay que advertir que no eran entregados directamente a los seises, sino al maestro de capilla, en calidad de tutor, y destinados a los gastos derivados

11r y 15v, caja 1097, Libro II (1675), f. 18v, caja 1097, Libro III (1690-1691), f. 11r, caja 2980, Libro VII (1650- 1674), ff. 10r, 43r, 58v, 173r, 212r, 263v, 294v, 348r, 382r, 415r, 425v, 645r, 659r, 689r y 718r. Cf. PeÑA Blanco, La música, 256-257.

51 AHDGu. Actas Capitulares, Tomo 10, ff. 147v-148r (Cabildo de 17-7-1621), Tomo 18, f. 485r (Cabildo de 24-5-1667). Cuentas de Fábrica Mayor, caja 2980, LibroVII (1650-1674), ff. 52r y 83r, caja 1097, Libro II (1675), f. 13r.

52 Cf. González Barrionuevo, Los seises, 48-50.

53 AHDGu. Actas Capitulares,Tomo 11, ff. 377v-378r (Cabildo de 3-3-1627). Cf. PeÑa Blanco, La música, 255-257.

54 Cf. José López-CALo, Documentario musical de la Capilla Real de Granada, vol. I, Granada, Centro de Documentación Musical de Andalucía, 2005, 185-186, 268270, 461-463. González BARRIONUEVo, Los seises, 29. 
de su cuidado. Este modo de proceder era el habitual en el resto de catedrales, como la de Sevilla; aunque, dependiendo de las posibilidades económicas, su ejercicio no estaba exento de irregularidades. En el caso de la catedral de Guadix, debido a la profunda crisis que atravesó la fábrica de la catedral en el último tercio del siglo XVII, se dieron situaciones controvertidas con relación al cuidado y sustento de los seises. De entre ellas, las más destacables fueron los pleitos por quién debía percibir las retribuciones delas actuaciones del grupo de seises cuando era otro músico, no el maestro de capilla, quien los custodiaba en su domicilio. ${ }^{55}$

\section{PRIMEROS DATOS Y CONFORMACIÓN DEL GRUPO DE SEISES}

A diferencia de otras catedrales españolas, la sede de Guadix no contó en esa época con un colegio dedicado a la enseñanza de su grupo de seises. Mientras que en catedrales como Toledo (1546), Granada (1621), Sevilla (1636) o León (1650) dispusieron la fundación o el ingreso de estos niños en instituciones que garantizaran su educación intelectual y religiosa, en Guadix pervivió la tradición de que los seises residieran en la casa del maestro de capilla, recibiendo de él una formación complementaria en moral, religión y humanidades. ${ }^{56}$

Sobre el posible origen del grupo de seises accitanos, no hemos encontrado, hasta la fecha, ningún dato en las fuentes conservadas en la catedral ni en otro archivo de la ciudad, como el de Protocolos Notariales. Pese a ello, el primer dato sobre la existencia de un niño seise se localiza en un acta capitular de 1547, donde se recoge que "Ximenez tiple de oy en adelante se viere reservado que no le seisen semana de cora ni calenda" ${ }^{57}$ Tras esta referencia, y como aludíamos en otro apartado anterior, en la Consueta de la catedral, de 1557, se recogen todas las obligaciones de estos niños cantores y las del maestro de capilla; por lo que podemos deducir que, ya en esa época, había niños cantores al servicio de la sede accitana y que algunos de

55 AHDGu. Actas Capitulares, Tomo 19, ff. 162v-163r (Cabildo de 3-7-1668), f. 217r (Cabildo de 15-11-1668). Cf. Peña Blanco, La música, 436-443.

56 Cf. González Barrionuevo, Los seises, 77-82. Pilar Bertos Herrera, Los seises de la catedral de Granada, Granada, Caja Provincial de Ahorros, 1988, 59-61. Peña BLANCO, La música, 142-144, 254-255.

57 HDGu. Actas Capitulares, Tomo 1, f. 9r (Cabildo de 8-1-1547). 
ellos participaban de la música polifónica interpretada por la capilla de música. En este sentido, en el documento encontramos la referencia a mozos de coro y acólitos que interpretaban la música propia reservada a los seises. Por ejemplo, en el capítulo 74, sobre la procesión del Domingo de Pascua, podemos leer lo siguiente:

[...] estaran dos acholitos de buenas voces a manera de angeles a los lados del arca con sus guinaldas i tienen un paño tendido uno de un cabo i otro de otro, i encima del Arca donde estan pintadas las insignias de la Pasion $\mathrm{i}$ mientras se dicen Laudes el Prior o el cura abra metido con toda la decencia el Sancto Sacramento en el Arca i esto asi puesto lleganse solamente tres acolitos en representación de las tres Marias al Monumento o a el lugar donde esta el Arca con la cruz diciendo a canto de organo por compostura o fabordón: Quire volvet nobis lapidem ab hostio monumento. ${ }^{58}$

Como queda reflejado en el texto, los niños cantores que intervienen en la procesión desempeñando el papel de las tres Marías, interpretan en polifonía una perícopa del evangelio de san Marcos. Por esta razón, aunque aparecen designados como acólitos, todo apunta a que se trataban de seises, encargados de la música polifónica en la capilla de música.

Como podemos comprobar de nuevo, la terminología empleada en las primeras fuentes conservadas es bastante ambigua. Por este motivo, debemos pensar que, aunque no como un grupo profesionalizado, desde el primer maestro de quien tenemos referencias, Francisco Maldonado (1526-1570), existían seises al servicio de la catedral de Guadix, ya que tenía la obligación de impartir lecciones de polifonía a los llamados mozos de coro. ${ }^{59}$ Sin embargo, a diferencia de lo dispuesto en la consueta de la catedral de Granada, en la accitana no aparece la obligación del maestro de capilla de custodiar a los seises en su casa. ${ }^{60}$ Así, no fue hasta el maestro de capilla interino Pedro de Avendaño (1604-1620), cuando en las actas capitulares se recoge su obligación de impartir lecciones de canto de órgano a los seises y

AHDGu. Consueta..., cap. 74, fol. 82r.

9 AHDGu. Actas capitulares, Tomo 1, f. 7r (Cabildo de 22-10-1545). Cuentas de Fábrica Mayor, caja 2979-a, Libro I (1556-1586), fol. 633r.

60 ACG. Consueta de ceremonias y gobierno, de la Santa Iglesia Catedral Apostólica y Metropolitana, de la ciudad de Granada, cap. 40, ff. 41v-42r. AHDGu. Consueta..., cap. 36, ff. 37v-38r. 
"a aquellos que quieran asistir", estando perfectamente reguladas y percibiendo por ello un salario. ${ }^{61}$

Tras estos primeros datos, hasta el magisterio de Bartolomé de Navarrete (1620-1625) no podemos afirmar que la sede accitana tuviera un grupo perfectamente organizado de seises o niños cantores. ${ }^{62}$ De hecho, la profesionalización de este grupo se constata en las fuentes, entre otros datos, porque se generaliza el término de seises para referirse a los niños cantores de polifonía, se dispone la obligación del maestro de custodiarlos y educarlos en su domicilio, se regula su asistencia al coro catedralicio en los llamados libros del punto y sus partidas salariales en los libros de fábrica. ${ }^{63}$ Junto a esto, el cabildo

AHDGu. Actas Capitulares, Tomo 1, f. 244r (Cabildo de24-1-1594).
AHDGu. Actas Capitulares, Tomo 10, f. 55r(Cabildo de 10-6-1620).

AHDGu. Actas Capitulares, Tomo 10, f. 112v (Cabildo de 26-1-1621), Tomo 10, f. 116v (Cabildo de 13-2-1621), Tomo 10, f. 206r (Cabildo de 22-4-1622), Tomo 11, f. 12r (Cabildo de 4-2-1625), Tomo 11, f. 63v (Cabildo de 4-7-1627), Tomo 11, ff. 103r-103v (Cabildo de 3-10-1625), Tomo 11, f. 336v (Cabildo de 23-11-1627), Tomo 11, f. 465v (Cabildo de 17-12-1628), Tomo 12, f. 88v (Cabildo de 10-7-1629), Tomo 12, f. 154v (Cabildo de 4-12-1629), Tomo 12., f. 245r (Cabildo de 7-6-1630), Tomo 12, f. 405v (Cabildo de 8-3-1631), Tomo 12, f. 409r (Cabildo de 18-3-1631), Tomo 12, f. 549r (Cabildo de 9-3-1632), Tomo 12, f. 711v (Cabildo de 5-7-1633), Tomo 13, f. 69r (Cabildo de 20-12-1634), Tomo 13, f. 258r (Cabildo dev12-21636), Tomo 13, f. 393r (Cabildo de 16-1-1637), Tomo 13, f. 480v (Cabildo de 29-8-1637), Tomo 13, f. 463r (Cabildo de 27-11-1637), Tomo 14, f. 31v (Cabildo de 20-12-1641), Tomo 14, f. 194r (Cabildo de 8-1-1644), Tomo 14, f. 249v (Cabildo de 1-7-1644), Tomo 14, f. 321r (Cabildo de 14-2-1645), Tomo 14, f. 466v (Cabildo de 14-8-1646), Tomo 14, f. 494r (Cabildo de 13-11-1644), Tomo 14, f. 496r (Cabildo de 23-11-1646), Tomo 16, f. 238r (Cabildo de 8-1-1655), Tomo 16, f. 405v (Cabildo de 25-6-1656), Tomo 16, f. 460r (Cabildo de 20-6-1657), Tomo 18, f. 309r (Cabildo de 11-3-1665), Tomo 18, f. 310r (Cabildo de 20-3-1665), Tomo 18, f. 394r (Cabildo de 20-2-1666), Tomo 18, f. 475r (Cabildo de 8-1-1667), Tomo 19, f. 53r (Cabildo de 11-1-1668), Tomo 19, f. 527r (Cabildo de 22-8-1670), Tomo 19, f. 558v (Cabildo de 2-3-1671), Tomo 20, f. 431r (Cabildo de 12-11-1675), Tomo 21, f. 221r (Cabildo de 12-7-1678), Tomo 22, f. 45r (Cabildo de 22-6-1679), Tomo 21, f. 179r (Cabildo de 5-7-1679), Tomo 22, f. 184r (Cabildo de 23-7-1680), Tomo 22, f. 507v (Cabildo de 23-10-1685), Tomo 23, f. 75v (Cabildo de 20-6-1687), Tomo 23, f. 88r (Cabildo de 7-11-1687), Tomo 23, f. 107r (Cabildo de 4-5-1688), Tomo 23, f. 165r (Cabildo de 22-11-1688), Tomo 23, f. 318r (Cabildo de 28-5-1691), Tomo 24, f. 10r (Cabildo de 12-2-1694), Tomo 24, f. 95r (Cabildo de 15-2-1696), Tomo 24, f. 100v (Cabildo de 31-3-1696), Tomo 24, f. 271r (Cabildo de 13-6-1699), Tomo 24, f. 302r (Cabildo de 23-7-1700). Libros del Punto, caja 2958, libro VII (626-1633), s/f (julio, 1626). Cuentas de Fábrica Mayor, caja 900, libro I (1613-1628), ff. 30r, 34r, 37v, 40r, 44r, 44v, 74v, 75v, 80v y 85r, caja 900, Contabilidad Fábrica y Obra II (1630-1633), ff. 
catedral dispuso que la formación que debía impartirles el maestro de capilla no solo fuera en música, sino en moral, religión y humanidades, teniendo, igualmente, que salir por las poblaciones vecinas a reclutarlos cuando fuera necesario.

Pese a todo ello, hasta la llegada del siguiente maestro de capilla, Juan de Villalobos (1627-1633), no quedó perfectamente conformado el grupo de seises, con un reglamento interno que establecía las obligaciones del maestro de capilla, el cabildo y las familias de los niños. De esta manera, tenían que vivir en la casa del maestro, quien asumía la responsabilidad de educarlos; por su parte, el cabildo se hacía cargo de los gastos derivados del vestido y la atención médica, mientras que las familias no podían poner ningún tipo de condición a tal respecto, so pena de ser expulsados. ${ }^{64}$

Por último, los datos recogidos a partir de ese momento en los libros del punto, nos permiten establecer la media del número de seises que estuvieron sirviendo en la catedral hasta finales del siglo XVII. Si al comienzo de nuestra investigación señalábamos que la media que se generalizó fue la de seis niños cantores, lo cierto es que este número variaba de una sede a otra, según sus posibilidades económicas. ${ }^{65}$ En el caso de la catedral de Guadix, la proporción se estableció en torno a los dos o tres niños al servicio de la capilla de música; si bien hubo momentos en los que contó con cinco, mientras que en otros solo logró tener uno. ${ }^{66}$

\section{EL GRUPO DE SEISES ACCITANOS DE LOS SIGLOS XVI-XVII}

Como ya indicábamos más arriba, los datos que se conservan sobre los niños que conformaron el grupo de seises de la catedral de Guadix se concentran a partir de finales del primer cuarto del siglo

6r, 8v, 11r y 15v, caja 2980, Libro VII (1650-1674), ff. 10r, 43r, 52r, 58v, 83r, 173r, 212r, 263v, 294v, 348r, 382r, 415r, 425v, 439r, 444r, 514r y 645v.

64 AHDGu. Actas Capitulares, Tomo 12, f. 499r (Cabildo de 28-11-1631).

65 Cf. GonzÁlez Barrionuevo, Los seises, 35-36. Peña Blanco, La música, 263

66 AHDGu. Libros del Punto, caja 2958, Libro VII (1626-1630), s/f, caja 2990, Libro VIII (1633-1647), s/f, caja 2991, Libro IX (1659-1664), s/f, caja 2992, Libro X (16641670), s/f, caja 2993, Libro XI (1670-1676), s/f, caja 2994, Libro XII (1679-1681), s/f, caja 295, Libro XIII (1682-1686), s/f, caja 3034, Libro XVI (1694-1698), s/f. 
XVII. ${ }^{67}$ Anterior a esta fecha, del único seise del que tenemos referencias es uno apellidado Ximénez, a quien el cabildo, en un acta de 1547, le reservaba de cantar en el coro. ${ }^{68}$ Sin embargo, a partir de 1620 se suceden los datos en las fuentes, permitiendo conocer a los protagonistas hasta finales de siglo. En este sentido, su estudio nos ha permitido establecer cómo el ingreso de algunos de los maestros de capilla accitanos llevó consigo la nueva incorporación de seises a la catedral; bien porque coincidiera con una campaña llevada a cabo por el cabildo o por la iniciativa de estos mismos músicos. ${ }^{69}$ Por esta razón, hemos creído conveniente identificar a los seises que estaban al servicio de la catedral durante los años de servicio de los distintos maestros de capilla a partir de finales del primer cuarto del siglo XVII.

El primero de estos maestros fue Bartolomé de Navarrete, que llegó a la sede de Guadix procedente de la catedral de Miranda de Duero en 1620, siendo canónigo de la misma. ${ }^{70} \mathrm{Tal}$ y como señalamos en un apartado anterior, bajo su magisterio se formalizó la obligación de los maestros de custodiar y educar a los seises. Además, en las fuentes consta que trajo consigo a dos niños tiples para el servicio de la catedral accitana, sin tener más datos sobre ellos. Durante los tres primeros años de su magisterio tuvo a su cargo a los seises Miguel Quesada, Pedro González y Diego Buendía. ${ }^{71}$ De este grupo solo conocemos que Quesada procedía de Úbeda y tenía una formación musical bastante completa y que los tres debieron entrar de muy niños al servicio de la catedral, en torno a los ocho o nueve años. Así, este grupo se mantuvo hasta el último año del magisterio de Navarrete, cuando se despidió a dos de ellos e ingresaron Francisco de Buendía y Gaspar de los Reyes.

67 Cf. Peña Blanco, La música, 263-264.

68 AHDGu. Actas Capitulares, Tomo 1, f. 9r (Cabildo de 8-1-1547).

69 AHDGu. Actas Capitulares, Tomo 10, f. 53v (Cabildo de 2-6-1620), Tomo 11, f. 85r (Cabildo de 30-8-1625), Tomo 11, f. 316v (Cabildo de 1-10-1627), Tomo 12, ff. 726r-726v (Cabildo de 30-8-1633), Tomo 13, ff. 99r-99v (Cabildo de 29-1-1635), Tomo 14, f. 216r (Cabildo de 1-4-1644), Tomo 16, ff. 638v-639r (Cabildo de 1711-1659, Tomo 24, f. 305r (Cabildo de 4-8-1700). Libros del Punto, caja 2990, Libro VIII (1633-1642), s/f (enero, 1635).

70 Cf. Peña Blanco, La música, 176-177.

71 AHDGu. Actas Capitulares, Tomo 10, f. 179v (Cabildo de 25-1-1622), Tomo 11, f. 12r (Cabildo de 4-2-1625), Tomo 11, f. 63v (Cabildo de 4-7-1625). Cuentas de Fábrica Mayor, caja 900, Libro I (1613-1628), ff. 37v, 40r y 44v. 
Tras Bartolomé de Navarrete y por quedar desierta la oposición convocada por el cabildo accitano a la plaza de maestro de capilla, ingresó como maestro interino el cantor contralto Pedro de Avendaño. ${ }^{72}$ Por este motivo, durante estos años, los seises pasaron a residir en el colegio seminario de san Torcuato. ${ }^{73}$ Debido a la avanzada edad y problemas de salud de Avendaño, el cabildo accitano escribió al maestro de capilla de Almería, Juan de Villalobos, para que viniera a servir a Guadix, otorgándole un salario de doscientos ducados y doce fanegas de trigo. ${ }^{74}$ En ese momento, el grupo de seises estaba formado por Pedro González y Gaspar de los Reyes; sin embargo, durante los primeros años de servicio, este maestro no quiso cumplir con la obligación de cuidar de ellos en su domicilio, por lo que el ministril Martín Mellado asumió esta responsabilidad, custodiando a los seises Pedro González y uno llamado Andrés de Buendía, de quien no tenemos más datos. ${ }^{75}$ Pese a ello, en estos años el cabildo intentó completar el grupo hasta los seis niños, recibiendo a dos hijos de un tenor de la capilla de música y a dos procedentes de Granada, que no fueron finalmente recibidos. ${ }^{76}$ Además, en ese momento se les concedieron dos becas del colegio seminario a los seises Pedro González y Gaspar de los Reyes, emprendiendo la carrera eclesiástica y convirtiéndose, más tarde, en sochantres de la catedral. ${ }^{77}$

A finales de 1630, junto a Andrés de Buendía, el grupo de seises estaba formado por Jerónimo de Benito y Francisco Losada, quien ingresó en el colegio seminario y llegó a ser años después maestro de capilla de la sede de Guadix. ${ }^{78}$ Igualmente, durante el magisterio de Villalobos, conocemos que un acólito de la catedral, Pedro Hernández, ingresó en el grupo de seises y que en 1632 entró

\footnotetext{
72 Cf. Peña Blanco, La música, 181-182.

73 AHDGu. Actas Capitulares, Tomo 11, ff. 313r-313v (Cabildo de 25-9-1627).

74 Cf. Peña Blanco, La música, 182-183.

75 HDGu. Actas Capitulares, Tomo 12, f. 67v (Cabildo de 10-7-1629). Libros del Punto, caja 2958, LibroVII (1626-1633), s/f (julio, 1629).

76 AHDGu. Actas Capitulares, Tomo 12, f. 88v (Cabildo de 28-9-1629), Tomo 12, ff. 99r-99v (Cabildo de 10-10-1629).

77 Ibidem, Tomo 12, f. 67v (Cabildo de 10-7-1629), f. 188v (Cabildo de 8-2-1630), f. 317r (Cabildo de 10-9-1630).

78 AHDGu. Libros del Punto, caja 2958, Libro VII (1626-1633), s/f (octubre, 1630, noviembre, 1630).
} 
a servir el primer seise capón del que tenemos referencias, llamado Jacinto Benito. ${ }^{79}$

En 1633, Juan de Villalobos consiguió la plaza de maestro de capilla de la catedral de Murcia, siendo reemplazado de manera interina por Baltasar Ruiz, cantor de la capilla de música. ${ }^{80}$ Dos años más tarde, en 1635, el cabildo accitano acordó convocar oposiciones al magisterio de capilla, ganándolas Luis de Garay. ${ }^{81}$ Sobre este músico, el compositor y musicólogo Francisco Asenjo Barbieri apunta que era natural de Beteta, en Cuenca; aunque se formó como músico en la sede de Granada, donde fue seise y maestro de la capilla de los músicos extravagantes de la ciudad. Cuando llegó a Guadix, el grupo de seises de su catedral estaba formado por los niños Francisco Valverde y otro apellidado Úbeda, sin tener más datos de ambos. ${ }^{82}$ $\mathrm{Al}$ año siguiente, por su mediación llegaron dos seises procedentes de Granada, Francisco Delgado y Pedro de Fuentes, y un hijo del ministril Jacinto López, llamado Pedro Molero. ${ }^{83}$ Este grupo se mantuvo más o menos estable durante los años de servicio en la sede accitana de Garay; si bien, en 1639, abandonó la catedral Pedro Molero, entrando de nuevo en el grupo de seises Bartolomé Sánchez. ${ }^{84}$

Tras la marcha de Luis de Garay a la sede primada de Toledo, donde ganó la oposición de maestro de capilla, el cabildo accitano

79 AHDGu. Actas Capitulares, Tomo 12, ff. 423r-423v (Cabildo de 13-5-1631), f. 441r (Cabildo de 8-7-1631). Libros del Punto, caja 2958, Libro VII (1626-1633), s/f (junio, 1631). Cuentas de Fábrica Mayor, caja 900, Contabilidad de Fábrica y Obra II (1630-1633), ff. 8v, 11r y 15v. Libros del Punto, caja 2958, LibroVII (16261633), s/f (agosto, 1632, noviembre, 1632).

80 Cf. Peña Blanco, La música, 185-186.

81 Cf. José López-Calo, "Garay, Luis de", en Enrique Casares Rodicio (dir.), Diccionario de la música española e hispanoamericana, vol. V, Madrid, S.G.A.E, I.N.A.E.M, I.C.C.M.U, 1999, 373. Carmelo, CABAllero FERnÁndeZ-RufETE, “El manuscrito Gayangos-Barbieri", Revista de Musicología, 12 (1989) 199-268. PeÑa Blanco, La música, 188-189.

82 AHDGu. Actas Capitulares, Tomo 13, f. 392v (Cabildo de 9-1-1637), ff. 391r-391v (Cabildo de 2-1-1637), f. 463r (Cabildo de 27-11-1637). Libros del Punto, caja 2990, Libro VIII (1633-1647), s/f (julio, 1635, febrero, 1636), s/f (diciembre, 1637).

83 AHDGu. Actas Capitulares, Tomo 13, f. 447r (Cabildo de 8-8-1637), Tomo 13, ff. 480v-481r (Cabildo de 29-8-1637), Tomo 13, f. 459v (Cabildo de 9-10-1637). Libros del Punto, caja 2990, LibroVIII (1633-1647), s/f (julio, 1637).

84 AHDGu. Libros del Punto, caja 2990, libro VIII (1633-1647), s/f (noviembre, 1640, julio, 1644). 
volvió a convocar oposiciones en $1644 .{ }^{85}$ En esta ocasión fueron varios los opositores, ganando finalmente la plaza Jacinto de Mesa. La musicología española describe a este músico como uno de los compositores más sobresalientes del panorama musical de la España del siglo XVII. ${ }^{86}$ A su llegada a la catedral de Guadix, el grupo de seises debió estar muy mermado en miembros, ya que el cabildo inició una campaña de búsqueda de candidatos por poblaciones más o menos cercanas a la ciudad. Fruto de esta iniciativa, entre 1645 y 1646, ingresaron cuatro niños cantores a la capilla de música, dos procedentes de Córdoba y dos de Alhama de Granada, sin tener más referencias de los mismos. ${ }^{87}$ Igualmente, en agosto de 1646, también ingresó un niño cantor llamado Francisco de Cózar, siendo enviado también al sochantre Gaspar de los Reyes para que recibiera lecciones de canto llano; iniciativa que provocó las quejas del maestro de capilla. ${ }^{88} \mathrm{No}$ obstante, este dato constata cómo el cabildo accitano promovía la formación musical de estos niños cuando veía posibilidades para que fueran de provecho, en un futuro, al servicio de la catedral.

Durante el resto de años del magisterio de Jacinto de Mesa, el cabildo siguió promoviendo la búsqueda de niños cantores. De hecho, en 1647 el grupo lo formaban dos seises, apellidados Águilas y Bahía, y se recibieron dos más procedentes de Úbeda, sin tener más noticias sobre ellos. ${ }^{89} \mathrm{Al}$ mismo tiempo, se recibieron para ser examinados a cuatro procedentes de distintas poblaciones de la diócesis de Guadix; aunque finalmente no fueron admitidos. Años más tarde, debió ingresar como seise Melchor de los Reyes, quien fue despedido en 1651, sin tener más referencias sobre él.

85 Cf. Peña Blanco, La música,192-193.

86 Cf. Mariano Soriano Fuertes, Historia de la música española desde la venida de los fenicios hasta el año 1850, Madrid, Bernabé Carrafa, 1850, 1855-1859. José CLimENT BARBER, "La música en Valencia durante el s. XVII", Anuario Musical 21 (1966) 211-241. Miguel Querol Gavaldá, "El archivo musical de la Colegiata de Jerez de la Frontera", Anuario Musical 30 (1975) 167-180. Isabel Ruiz de Elvira Serra, Catálogo de villancicos de la Biblioteca Nacional. Siglo XVII. Madrid, Ministerio de Cultura, 1992, 178-180.

87 AHDGu. Actas capitulares, Tomo 14, ff. 321r-321v (Cabildo de 14-2-1645), Tomo 14, f. 494r (Cabildo de 13-11-1646).

88 Ibidem, Tomo 14, f. 466v (Cabildo de 14-8-1646), Tomo 14, f. 468r (Cabildo de 17-8-1646).

89 AHDGu. Libros del Punto, caja 2990, libro VIII (1633-1647), s/f (septiembre, 1647). 
Tras la marcha de Jacinto de Mesa a la catedral de Murcia y un breve servicio de meses del maestro Francisco Losada, el cabildo accitano escribió a Mateo Sánchez de Fonseca para que viniera a servir como maestro de capilla..$^{90}$ De su biografía, conocemos que en ese momento se encontraba en la capilla del Salvador de Úbeda como maestro y que era natural de Guadix. Pese a que el cabildo accitano le pidió que trajese consigo a dos niños tiples para que sirvieran de seises, hasta el año 1656 no tenemos datos sobre quiénes eran los que conformaban este grupo: Juan de Rodejo, Salazar y Pedro Fernández Valencia. ${ }^{91}$ La difícil situación económica que atravesó la fábrica de la catedral en esos años se pone de manifiesto en la escasez de datos sobre los niños cantores que sirvieron en la catedral. ${ }^{92}$ Así, solo consta que en 1657 ingresó Antonio Rodríguez y que en 1659 la capilla contaba con los seises Bartolomé Payán y otro apellidado Rutia. ${ }^{93}$

A finales de 1659, Mateo Sánchez de Fonseca se trasladó como maestro a la catedral de Baeza, convocando el cabildo de Guadix oposiciones al magisterio de capilla. En esta ocasión, fue el dictamen del obispo José Laínez quien ratificó la elección de Bartolomé de Alaminos como maestro, en contra del resultado del concurso que daba como ganador a Antonio Vargas, maestro procedente de Lorca. Sobre Alaminos, conocemos que venía de la capilla del Salvador de Úbeda, donde había ejercido como maestro de capilla, y que permaneció hasta su muerte en la catedral de Guadix, a principios del siglo XVIII.

Durante los veinte primeros años de su magisterio en la sede accitana, la mayoría de niños cantores que sirvieron como seises procedieron de poblaciones de la misma diócesis. Así, en 1665, la

90 Cf. Máximo Pajares Barón, Francisco de Losada (h.1612-1667). Vida y obra de un maestro de capilla, Cádiz, Universidad de Cádiz, 1993, 18-28. Manuel BARRA RodríguEz, "Fr. Francisco de Losada, monje del monasterio de Bornos, maestro de capilla de la catedral de Cádiz", Gades 11 (1983) 223-239. Peña Blanco, La música, 194-195.

91 AHDGu. Actas Capitulares, Tomo 16, f. 238r (Cabildo de 8-1-1655), Tomo 16, f. 253v (Cabildo de 2-4-1655). Cuentas de Fábrica Mayor, caja 2980, Libro VII (1650-1674), fol. 212r.

92 Cf. Peña Blanco, La música, 195-198.

93 AHDGu. Actas Capitulares, Tomo 16, f. 405r (Cabildo de 27-10-1656), Tomo 16, f. 460r (Cabildo de 20-6-1657). Libros del Punto, caja 2991, Libro IX (1659-1664), s/f (agosto, 1659). 
capilla contaba con Torquato Martínez, procedente de la Puebla de Don Fadrique, y Cristóbal de Oreja, natural de Gor. ${ }^{94}$ Junto a ellos, el grupo se completaba con Francisco Donato y, en 1666, con Alonso Merino, que ingresó también como aprendiz con el grupo de ministriles de la catedral. ${ }^{95}$ Junto a ellos, en 1670, entraron a servir como seises Leonardo Peláez, procedente de Zújar, en la diócesis de Guadix, y Juan Sáez, de quien no poseemos más referencias. Sin embargo, durante estos años, el cabildo tuvo que amonestar a Alaminos por descuidar sus funciones en el cuidado y el aseo de los seises, teniendo que desempeñar este servicio el ministril Melchor Dardo durante varios meses, en $1670 .{ }^{96}$

Tras este episodio, entre los años 1671 y 1673, ingresó en la capilla de música una serie de niños cantores que sobresalieron por su formación musical. De hecho, a la mayoría de ellos se les concedió una beca del colegio seminario, donde emprendieron la carrera eclesiástica, compatibilizándolo con su servicio en la catedral. El primero de ellos fue Juan González, que pasó a servir en la capilla de música en 1671; aunque también suplió al organista y cantó en el coro de los oficios, algo que le valió que le concedieran una beca en $1672 .{ }^{97} \mathrm{Al}$ año siguiente, en 1673, ingresó Lucas de la Peña, quien llegó a participar, una vez que se le concedió una beca en 1677, como cantor contralto de la capilla de música y suplente del organista. ${ }^{98}$ Junto a ellos, el grupo de seises lo completaban Manuel Buitrago, hermano del sochantre de la catedral Juan Buitrago, y otro apellidado Salazar. ${ }^{99} \mathrm{~A}$

94 AHDGu. Actas Capitulares, Tomo 18, f. 309r (Cabildo de 11-3-1665), Tomo 18, f. 310r (Cabildo de 20-3-1665).

95 AHDGu. Actas Capitulares, Tomo 18, ff. 394v-395r (Cabildo de 20-2-1666). Libros del Punto, caja 2992, Libro X (1664-1670), s/f (diciembre, 1667). Libros del Punto, caja 2992, Libro X (1664-1670), s/f (mayo, 1665), s/f (mayo, 1667, noviembre, 1667).

96 AHDGu. Actas Capitulares, Tomo 19, ff. 162v-163r (Cabildo de 3-7-1668), Tomo 19, f. 512r (Cabildo de 22-8-1670).

97 AHDGu. Libros del Punto, caja 2993, Libro XI (1670-1676), s/f (noviembre, 1671), s/f (noviembre, 1671, enero, 1672).

98 AHDGu. Actas Capitulares, Tomo 21, f. 169v (Cabildo de 6-12-1677), Tomo 22, f. 179r (Cabildo de 15-7-1679), Tomo 21, f. 88r (Cabildo de 23-4-1677). Libros del Punto, caja 2993, Libro XI (1670-1676), s/f (diciembre, 1673), caja 2995, Libro XIII (1682-1686), s/f (octubre, 1682).

99 AHDGu. Actas Capitulares, Tomo 21, f. 218r (Cabildo de 2-7-1678). Libros del Punto, caja 2994, Libro XII (1679-1681), s/f (setiembre, 1679). 
pesar de las distintas campañas de búsqueda de estos niños por poblaciones cercanas, como Jódar en la provincia de Jaén, este grupo se mantuvo invariable hasta 1681; en el que aparecen Buitrago, Salazar y otro apellidado Ramírez. ${ }^{100}$

Además de los anteriores, en ese mismo año de 1681 ingresaron los seises Baltasar de los Reyes y otro apellidado Moreno. De este último, conocemos que tenía un carácter difícil, por lo que el cabildo le prohibió entrar en el coro, salvo para cantar los villancicos "por ser necesario". ${ }^{101}$ Este grupo de niños seises se mantuvo hasta 1684, año en el que abandonan la catedral Moreno y Buitrago, y pasaron a servir de seises Juan del Hoyo y Juan Ortega; pero debido a la avanzada edad del maestro Alaminos, ambos fueron custodiados por el ministril Antonio Rivera. ${ }^{102}$ No obstante, al año siguiente, Juan del Hoyo fallecía y Juan Ortega era despedido por falta de salud, entrando en su lugar un seise llamado Francisco de Borja. ${ }^{103}$

En 1687, la capilla contaba tan solo con un seise, por lo que el cabildo envió al ministril Francisco Dávalos para que fuera a Úbeda en busca de candidatos. ${ }^{104}$ Fruto de esta empresa, ingresó como seise de la catedral Miguel Jerónimo, a la edad de ocho años y pasando a ser cuidado en casa de aquel ministril. ${ }^{105} \mathrm{~A}$ partir de ese momento y hasta finales de siglo, los niños que pasaron a servir como seises de la catedral de Guadix procedieron de poblaciones de la misma diócesis o eran familiares de otros miembros de su capilla de música. Así, en 1685 ingresó Bartolomé de Moya, natural de Lanteira, que fue despedido poco después, pero incorporado de nuevo al grupo de seises en $1689 .{ }^{106}$

100 AHDGu. Actas Capitulares, Tomo 22, f. 184r (Cabildo de 23-7-1680), Tomo 22, f. 184r (Cabildo de 23-7-1680). Libros del Punto, caja 2994, Libro XII (1679-1681), s/f (septiembre, 1680, julio, 1681).

101 AHDGu. Actas Capitulares, Tomo 22, f. 177r (Cabildo de 11-6-1679).

102 AHDGu. Libros del Punto, caja 2995, Libro XIII (1682-1686), s/f (febrero, 1685).

103 AHDGu. Actas Capitulares, Tomo 22, f. 456r (Cabildo de 7-7-1685), Tomo 22, ff. 507r-507v (Cabildo de 23-10-1685). Libros del Punto, caja 2995, Libro XIII (16821686), s/f (junio, 1685).

104 AHDGu. Actas Capitulares, Tomo 23, f. 75v (Cabildo de 20-5-1687).

105 Ibidem, Tomo 23, f. 88v (Cabildo de 7-11-1687), Tomo 23, f. 107v (Cabildo de 4-5-1688).

106 AHDGu. Actas Capitulares, Tomo 23, f. 165r (Cabildo de 22-11-1685). Libros del Punto, caja 2995, Libro XIII (1682-1686), s/f (mayo, 1685, enero, 1689). 
Dos años más tarde, en 1691, entró a servir como seise Pedro Ibáñez, sobrino del cantor contralto Pedro Ibáñez, y, en 1694, Francisco Rosillo, procedente de La Calahorra. ${ }^{107}$ Igualmente, en 1695, entró como seise Domingo Requena, de quien no podemos precisar si era familiar de un cantor de la capilla accitana con el mismo apellido. ${ }^{108}$ Pese a estas incorporaciones, para 1696 la catedral solo contaba con un seise, Francisco Rosillo. Por este motivo, el cabildo decidió recibir a dos niños procedentes de Baza, Juan de Torres y Antonio Díaz, que fueron examinados por el maestro de capilla. ${ }^{109}$ Finalmente, en 1699, ingresaba como seise Tomás Ibáñez, siendo el último niño cantor de la sede accitana del siglo XVII, sin tener más datos sobre su estancia en Guadix. ${ }^{110}$

\section{CONCLUSIONES}

Pese a tener referencias desde la primera mitad del siglo XVI, la catedral de Guadix no tuvo un grupo conformado de seises hasta prácticamente el segundo cuarto del siglo XVII. Así, a partir de esta fecha, la sede accitana contó con un grupo profesionalizado de estos niños, viviendo bajo la tutela del maestro de capilla y recibiendo de él, no solo una formación musical, sino también en religión, moral y humanidades. Sin embargo, al contrario que en otras sedes, la catedral accitana no contó con un colegio de seises para la formación intelectual y religiosa de estos niños durante el marco cronológico objeto de nuestro estudio.

Por otra parte, la situación económica por la que atravesó la fábrica de la catedral fue un factor condicionante en relación con los procesos de selección de los futuros seises. Por este motivo, en la mayoría de los casos, el cabildo se vio obligado a enviar al maestro de capilla, o a alguien delegado por él, por poblaciones más o menos cercanas a Guadix en busca de estos niños cantores. A este respecto, buena parte de la nómina de seises que pasó por la catedral en

\footnotetext{
107 AHDGu. Actas Capitulares, Tomo 24, f. 100v (Cabildo de 31-3-1691). Libros del Punto, caja 3034, Libro XVI (1694-1698), s/f (abril, 1694).

108 AHDGu. Actas Capitulares, Tomo 24, f. 73r (Cabildo de 26-5-1695).

109 AHDGu. Actas Capitulares, Tomo 24, f. 95r (Cabildo de 15-2-1696). Libros del Punto, caja 3034, Libro XVI (1694-1698), s/f (marzo, 1696).

110 AHDGu. Actas capitulares, Tomo 24, f. 261r (Cabildo de 13-6-1699), Tomo 24, f. 271r (Cabildo de 12-11-1699).
} 
esa época procedía de Úbeda; aunque hay que tener en cuenta que en esta ciudad había centros religiosos que contaban con grupos de músicos asalariados, como la capilla del Salvador. Junto a esta iniciativa por parte del cabildo, también ingresaron a servir como seises algunos familiares de ministriles y cantores de la catedral, pero en menor número.

No obstante, la permanencia de la mayoría de los seises que pasaron por Guadix en el siglo XVII solo llegó al año. Las razones de esto pueden ser varias, bien por la difícil situación económica de la fábrica de la catedral en esa época, bien porque simplemente los candidatos no reunieron las cualidades vocales necesarias para desempeñar sus funciones. Sin embargo, aquellos que permanecieron al servicio de la catedral, una vez mudaron la voz, tuvieron una proyección profesional en el campo de la música. De entre ellos, hubo un buen porcentaje de seises que logró una beca del colegio seminario, emprendiendo la carrera eclesiástica y perfeccionándose en el canto llano. De hecho, algunos de ellos llegaron a desempeñar el cargo de sochantre, tanto en la catedral accitana como en otros centros religiosos y sedes importantes. Junto a ellos, también hubo antiguos seises que pasaron a formarse como aprendices con el grupo de ministriles de la catedral, consiguiendo de este modo un medio de vida. Pese a ello, también hubo seises que tuvieron que ser expulsados por el cabildo por su mal comportamiento, algo que no hace sino evidenciar cómo algunos de estos niños pasaban a servir en la catedral con un déficit de educación, procedentes de estratos sociales marginados.

Con respecto al número de seises, el factor económico también fue decisivo en este aspecto. Así, se constata cómo el cabildo llevó a cabo distintas campañas de búsqueda de estos niños cuando las posibilidades de la fábrica accitana así lo permitieron. De igual modo, en varias ocasiones, el esfuerzo económico que supuso la convocatoria de oposiciones para la recepción de un nuevo maestro de capilla llevó consigo la petición para que trajese algún niño cantor; ya que procedían de otros centros religiosos donde habían tenido seises a su cargo, solucionando así dos necesidades en una. De esta manera, la catedral de Guadix contó con una media de entre dos y cinco niños cantores en el siglo XVII; aunque hubo momentos en los que tan solo tuvo uno de estos. Además, en la nómina de seises que pasaron por esta seo se repiten algunos apellidos, como Buendía, Buitrago, Quesada o de los Reyes, que ponen de manifiesto la existencia de 
verdaderas sagas de músicos al servicio de la catedral; algo por otra parte normal, ya que un alto porcentaje era procedente de poblaciones de la misma diócesis y muy cercanas a la ciudad.

En resumen, con este trabajo de investigación damos a conocer los factores y agentes que intervinieron en el desarrollo del grupo de seises de la catedral de Guadix, desde los primeros datos de niños al servicio de la catedral en el siglo XVI hasta su profesionalización en el siglo XVII. De igual manera, la sede accitana es analizada, no solo como un espacio de alabanza y expresión artística, sino también como una plataforma de promoción para muchos de los niños cantores de esa época. De hecho, algunos de los seises que prestaron su servicio en Guadix tuvieron la oportunidad de seguir formándose, una vez que mudaban la voz, y emprender una carrera como músicos profesionales en la misma catedral y en otros centros religiosos importantes. 